\title{
Effect of RF Sputtering Power and Deposition Time on Optical and Electrical Properties of Indium Tin Oxide Thin Film
}

\author{
Abdelaziz Tchenka $\mathbb{D}^{1}{ }^{1}$ Abdelali Agdad, ${ }^{1}$ Mohamed Cheikh Samba Vall, ${ }^{2}$ \\ Salma Kaotar Hnawi, ${ }_{1}^{1}$ Abdelfattah Narjis, ${ }^{1}$ Lahcen Nkhaili ${ }^{D},{ }^{1}$ Elalami Ibnouelghazi, ${ }^{1}$ \\ and Elmaati Ech-Chamikh ${ }^{1}$ \\ ${ }^{1}$ Nanomaterials for Energy and Environment Laboratory, Physics Department, Faculty of Sciences Semlalia, \\ Cadi Ayyad University, P. O. Box 2390, Marrakech 40000, Morocco \\ ${ }^{2}$ Laboratory of Renewable Energy and Environment, Faculty of Science Kenitra, Ibn Tofail,University, P. O. Box 133, \\ Kenitra, Morocco \\ Correspondence should be addressed to Abdelaziz Tchenka; abdelaziz.tchenka@gmail.com
}

Received 9 January 2021; Revised 20 July 2021; Accepted 12 August 2021; Published 30 August 2021

Academic Editor: Mikhail Zheludkevich

Copyright (c) 2021 Abdelaziz Tchenka et al. This is an open access article distributed under the Creative Commons Attribution License, which permits unrestricted use, distribution, and reproduction in any medium, provided the original work is properly cited.

\begin{abstract}
Indium tin oxide (ITO) films are widely used as transparent conducting electrodes in solar cells, gas sensors, and car windows because of their high electrical conductivity and good optical transparency in the visible region. In this work, ITO thin films were prepared by cathodic radio-frequency (RF) sputtering using an ITO target with $90 \% \mathrm{In}_{2} \mathrm{O}_{3}$ and $10 \% \mathrm{SnO}_{2}$. The structural properties were studied by X-ray diffraction (XRD), scanning electronic microscopy (SEM), and X-ray reflectometry (XRR). Electrical measurements were performed by applying the four-point method and studying the Hall Effect. Finally, optical properties were taken by the UV-Vis-NIR spectrophotometry. The effect of the RF power and deposition time on optical and electrical properties was investigated. It is shown that by using a RF power of 110-80 W, one can prepare crystalline samples with low resistivity, which is an aimed property for TCO semiconductors. Electrical measurements revealed that the resistivity decreases by increasing the RF power and/or the deposition time.
\end{abstract}

\section{Introduction}

Tin-doped indium oxide (ITO) thin films have attracted the attention of many researchers owing to their good conductivity and high optical transmittance ( 95\%) in the visible region [1]. Besides, ITO is an $n$-type semiconductor [2] with an energy band gap of $3.5 \mathrm{eV}$. Consequently, it exhibits high concentration of free electrons. These properties make it useful in several applications, including protective coatings [3], solar cells [4], gas sensors [5], reflecting windows [6], transparent electrodes for flat panel displays [7], organic light emitting diodes [8], plasma display panels [9], lenses [10], and car windows [11]. Sputtering ITO properties depend on various deposition condition parameters, such as initial pressure, RF power [12], argon pressure [13], deposition time [14], angle of incidence of the deposition on the substrate [15], target-to-substrate distance, substrate type [16], film thickness [17], temperature of the substrate [7], and oxygen flow rate [1].

Research works on ITO films focused on several methods of elaboration such as dip coating [18], thermal evaporation [19], spray pyrolysis [20], electron beam evaporation [21], electrochemical deposition [22], chemical vapor deposition (CVD) [23], evaporation in reactive atmosphere or vacuum [24], pulsed laser deposition (PLD) [25], direct current (DC) magnetron sputtering [26], and radio-frequency $(R F)$ sputtering $[18,26,27]$. The $R F$ sputtering is one of the most widely used deposition techniques in many industries to prepare transparent and conductive thin films due to its advantages of good film adhesion, reproducibility, high deposition rate, good homogeneity, and suitability for large areas [28]. 
In this study, we investigated the effect of RF sputtering power and deposition time on optical and electrical properties of ITO thin films. The RF sputtering method was used to ensure good adhesion. In fact, the expansion coefficient mismatch between the ITO films could create microcracks and consequently damage the film. The variation in crystal structure, resistance, and optical properties induced in the ITO samples is discussed in detail. It was found that these ITO films have good optical and electrical properties. In particular, the sheet resistance is lower than that reported in some reports.

\section{Experimental Details}

ITO films were deposited at room temperature by the RF sputtering technique in an Alcatel SCM 451. A schematic diagram of the RF sputtering that we used in this study is shown in Figure 1. Initially, the glass substrates were cleaned using acetone and distilled water in ultrasonic bath for 15 min prior to deposition, and the sputtering chamber was evacuated to less than $2 \times 10^{-6}$ mbar. Besides, the substratetarget distance was fixed at $7 \mathrm{~cm}$. The target purity is $99.99 \%$, and its diameter is $10 \mathrm{~cm}$. Furthermore, high purity argon gas $(99.999 \%)$ was introduced with a pressure of $10^{-2}$ mbar as shown in Table 1. Before each deposition, the target was presputtering in argon plasma for $20 \mathrm{~min}$ to remove contaminants. No oxygen was added during deposition. The films are deposited at different RF powers $(20,50,80$, and $110 \mathrm{~W})$ for different deposition times (20, 40, and $60 \mathrm{~min}$ ) and are shown in Figure 2.

The structural characterization was performed using the Rigaku Smart lab SE X-ray diffractometer in the $2 \theta$ range $20-80^{\circ}$ based on the $\mathrm{Cu}(\mathrm{K} \alpha)$ radiation in the Bragg Brentano configuration $(\lambda=1.5418 \AA$ ). SEM morphology images were used to observe the surfaces of ITO films on the substrate. The optical transmittance was measured in the wavelength range 200-2000 $\mathrm{nm}$, using an UV-Vis-NIR spectrometer (Shimadzu UV-PC spectrophotometer). Electrical resistivity was measured using a lab-manufactured device, to apply the four-point probes method, with the KEITHLEY A Tektronix Company generator/counter (6430 Sub-Femtoamp Remote Source Meter). The TESCAN VEGA3 scanning electron microscope was used to analyze the surface morphology.

\section{Results and Discussion}

XRD spectra of the ITO films prepared with various RF powers and different deposition times are shown in Figure 3. It is observed that the preferred orientation does not depend on the power nor the time as all the crystalline film exhibit (222) preferred orientation only. The spectra corresponding to $20 \mathrm{~W}$ reveal that the films are amorphous for all deposition times, or the film thickness is not sufficient. In some previous works, (see, e.g., [7, 9, 29]), no characteristic diffraction peak of ITO was observed for the films with film with thickness lower than $80 \mathrm{~nm}$. The ITO film was found to go from an amorphous state to a microcrystalline or polycrystalline state with increasing the

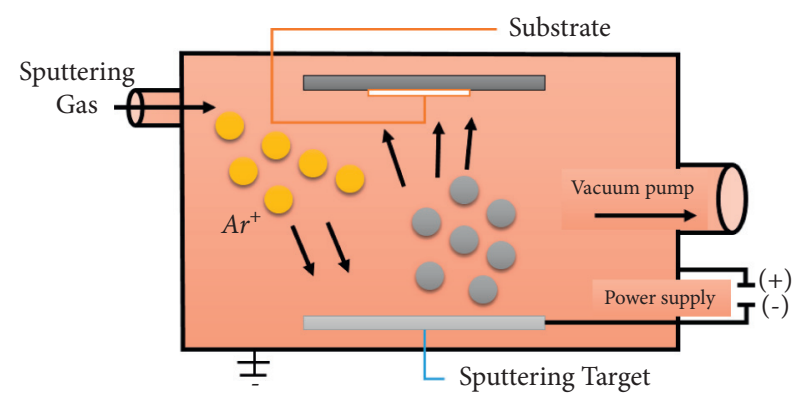

FIGURE 1: Schematic diagram of the RF sputtering.

TABle 1: Conditions of RF sputtering.

\begin{tabular}{lc}
\hline Parameter & Value \\
\hline Power & $\mathbf{2 0 ~ W , ~} \mathbf{5 0} \mathbf{~ W}, \mathbf{8 0 ~ W , ~ 1 1 0 ~ W ~}$ \\
Deposition times & $20 \mathrm{~min}, 40 \mathrm{~min}, 60 \mathrm{~min}$ \\
Residual pressure & $3.10^{-6} \mathrm{mbar}$ \\
Target & $10 \mathrm{~cm}$ \\
The diameter of target & ITO with $90 \% \mathrm{In}_{2} \mathrm{O}_{3}$ and $10 \% \mathrm{SnO}_{2}$ \\
Temperature & Room temperature \\
Substrate & Glass substrate \\
Target-to-substrate & $10 \mathrm{~cm}$ \\
distance & $10^{-2} \mathrm{mbar}$ \\
Argon pressure &
\end{tabular}

RF power as shown in Figure 3. The peak is first observed followed by the (222) orientation, and then the (400), (440), and (622) orientations are observed. The observed results are similar to those reported by Ghorannevis et al. [30].

To study the effects of the grain size of ITO films on electrical and optical properties, the average crystallite size was calculated using Scherrer's equation as follows:

$$
D=\frac{k \lambda}{\beta \cos \theta}
$$

where $\beta$ is the full width at half maximum (FWHM) of the different peaks, $\lambda$ is the X-ray wavelength $(\mathrm{Cu}-K \alpha=1.5418 \AA$ ),$k=0.94$ is the shape factor, and $2 \theta$ is the peak position. It is observed that the crystallite size is between $5 \mathrm{~nm}$ and $37 \mathrm{~nm}$ and is increased by increasing the deposition times as shown in Figure 4. In addition, the crystallite size is better as the sputtering power of $80 \mathrm{~W}$. Moreover, the dislocation density $(\delta)$ and the microstrain $(\varepsilon)$ of the thin films were calculated from the following equations:

$$
\begin{aligned}
& \delta=\frac{1}{D^{2}}, \\
& \varepsilon=\frac{\beta \cos \theta}{4} .
\end{aligned}
$$

The analysis of the evolution of one of them is therefore sufficient. Furthermore, for the deposition times 40 and $60 \mathrm{~min}$, the dislocation is constant by increasing the power. This indicates that the length of the lines per volume unit of 


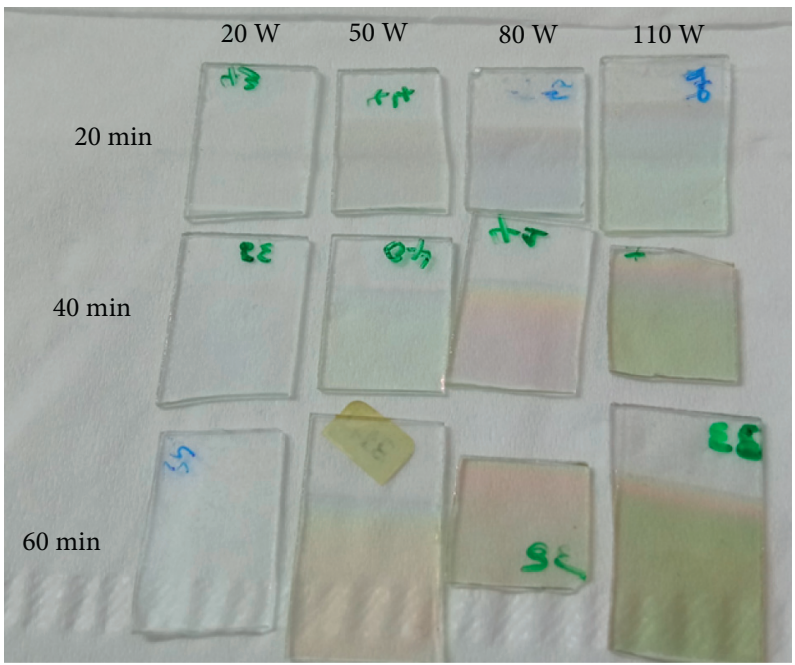

FIGURE 2: Images of ITO prepared by RF sputtering with various powers and different deposition times.

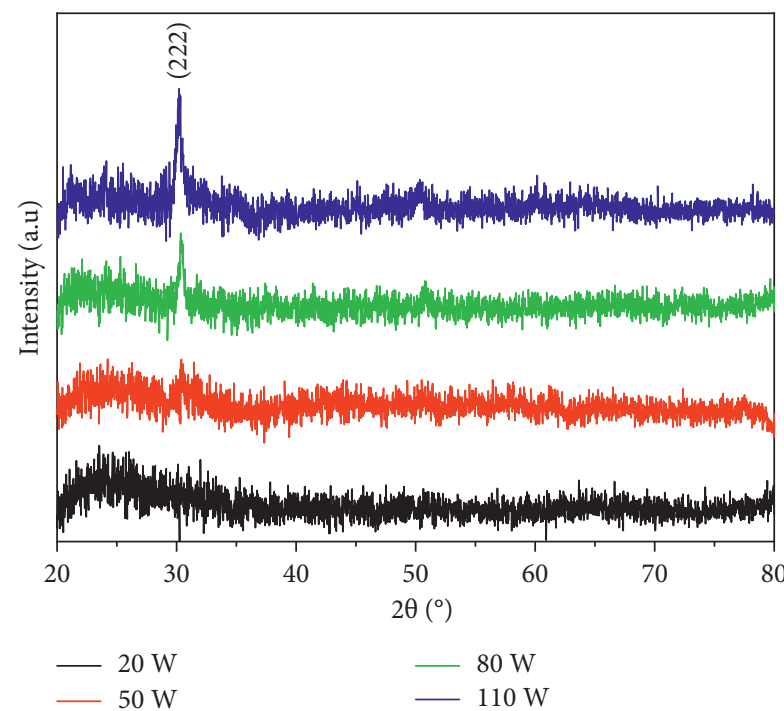

(a)
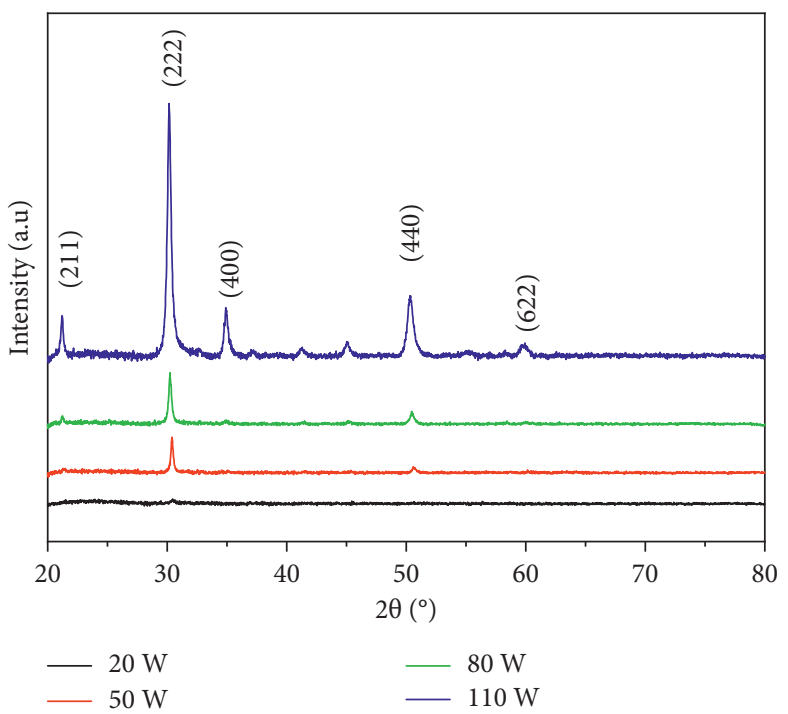

(b)

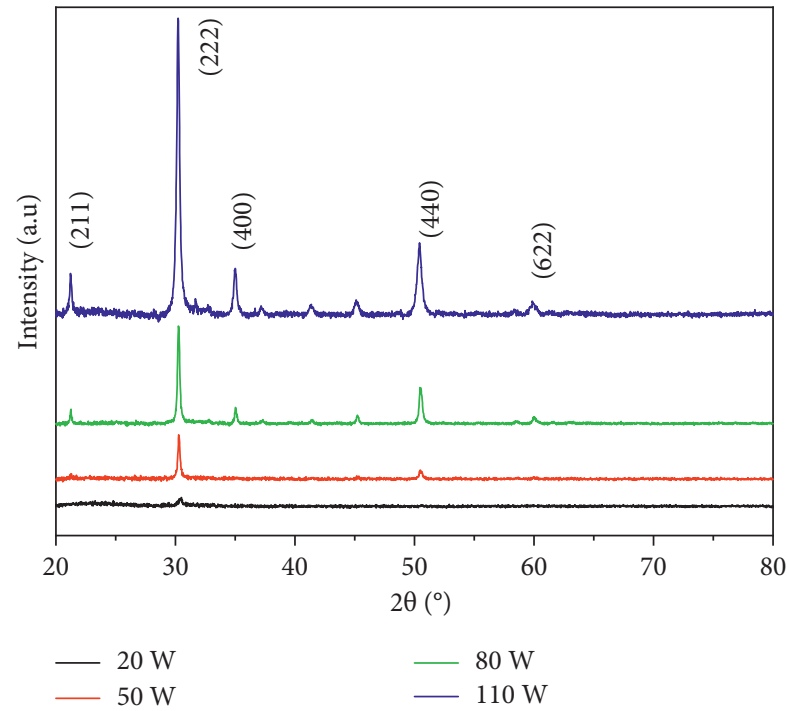

(c)

FIGURE 3: XRD patterns for ITO films deposited with various powers and different deposition times: (a) $20 \mathrm{~min}$; (b) $40 \mathrm{~min}$; (c) $60 \mathrm{~min}$. 

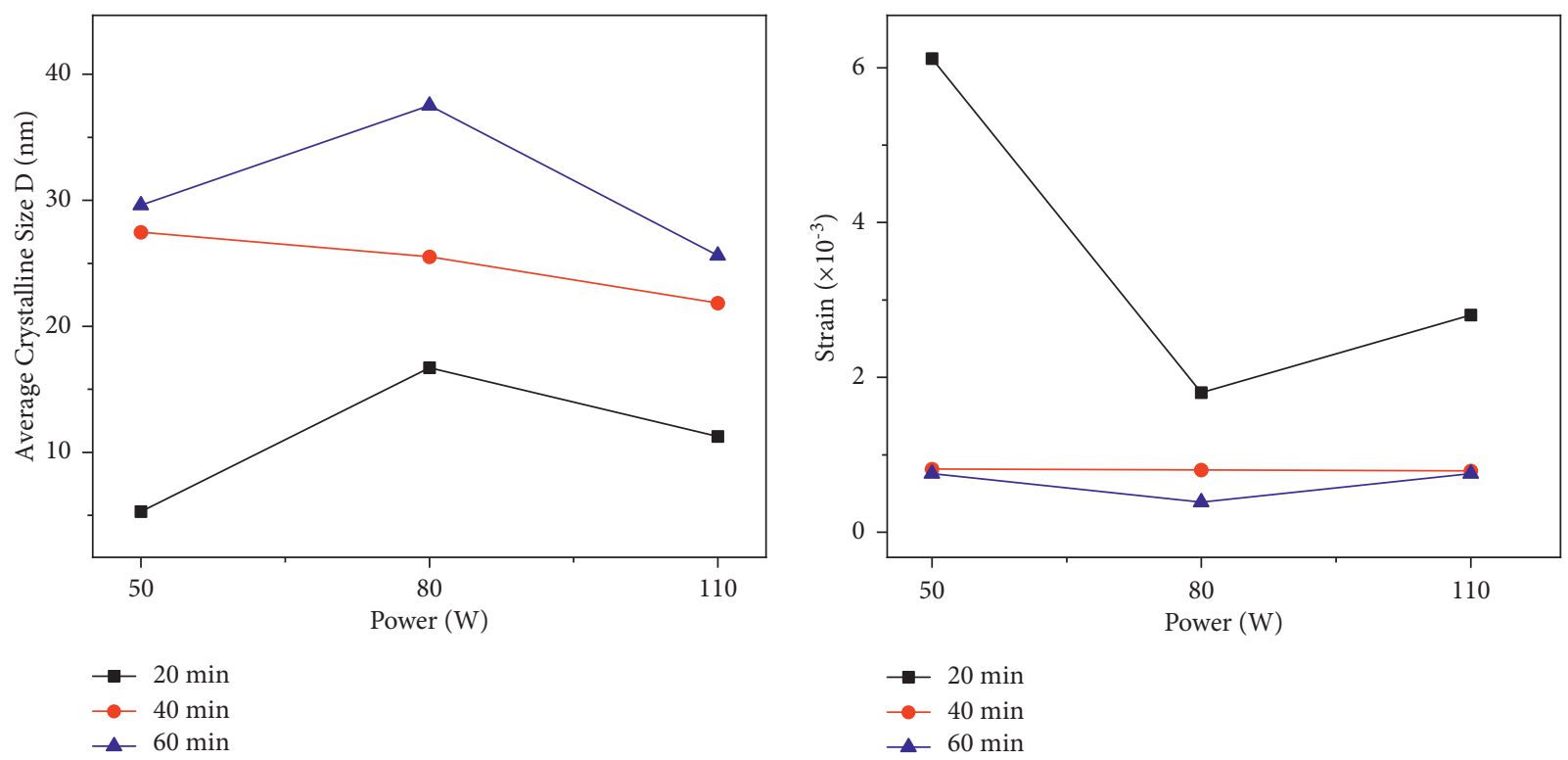

(a)

(b)

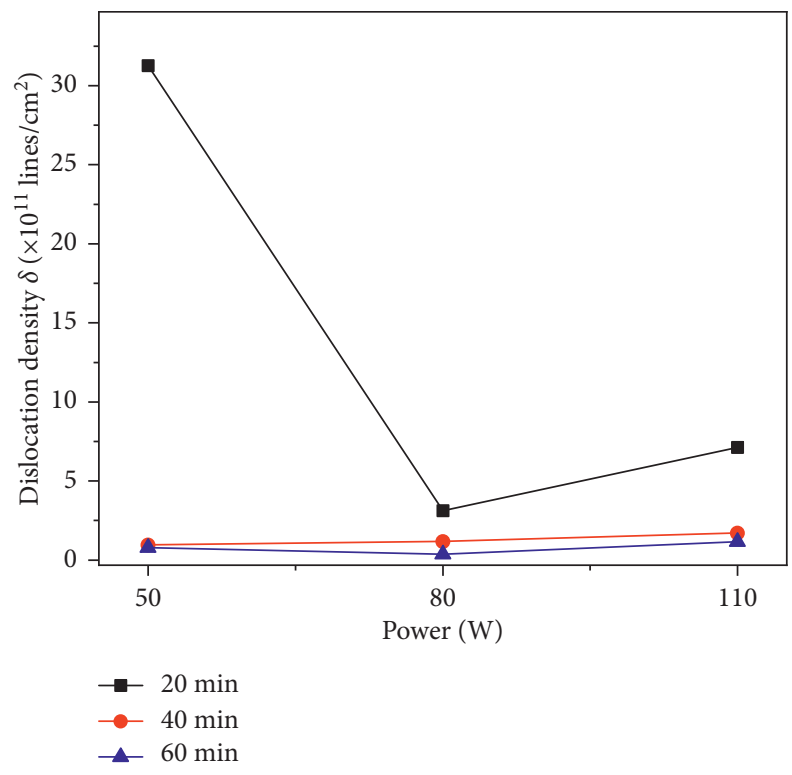

(c)

FIgURE 4: (a) Crystallite size; (b) microstrain; and (c) dislocation density of the ITO films deposited with various powers and deposition times.

the crystal is constant. In addition, the structural disorder and defects in ITO lattice also decrease for the deposition time of $20 \mathrm{~min}$.

3.1. X-Ray Reflectometry. The XRR patterns of the synthesized ITO thin films at various $R F$ powers and different deposition times are shown in Figure 5. For all samples, the reflectometry drops beyond a critical angle, which will be used to determine the sample density and thickness. In addition, it should be noted that some curves exhibit intensity oscillations due to the phenomenon of $\mathrm{X}$-rays interference. The films thickness $d$ can be calculated by equation (4) where $\alpha_{\mathbf{c}}$ is the critical angle, $\mathbf{m}$ is the interference order, $\mathbf{p}_{1}$ is the order of the first fringe observed on the reflectometry spectrum, and $\lambda$ is the wavelength of $\mathrm{Cu}-\mathrm{K} \alpha$ radiation [31]:

$$
\frac{\mathbf{m}-1}{2}=\frac{2 \mathbf{d}}{\lambda} \sqrt{\boldsymbol{\alpha}_{\mathbf{m}}^{2}-\boldsymbol{a}_{\mathrm{c}}^{2}}-\mathbf{p}_{1} \text {. }
$$

The critical angle increases, by increasing the RF power, between 0.32 and 0.35 . The density $\rho$ is related to the electronic density of the material by the following equation [32]: 


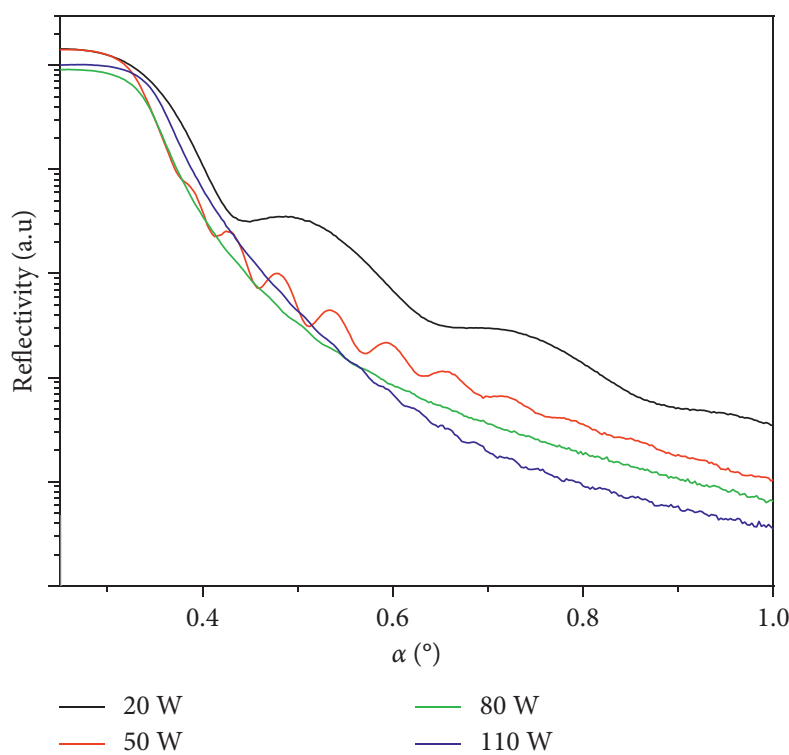

(a)

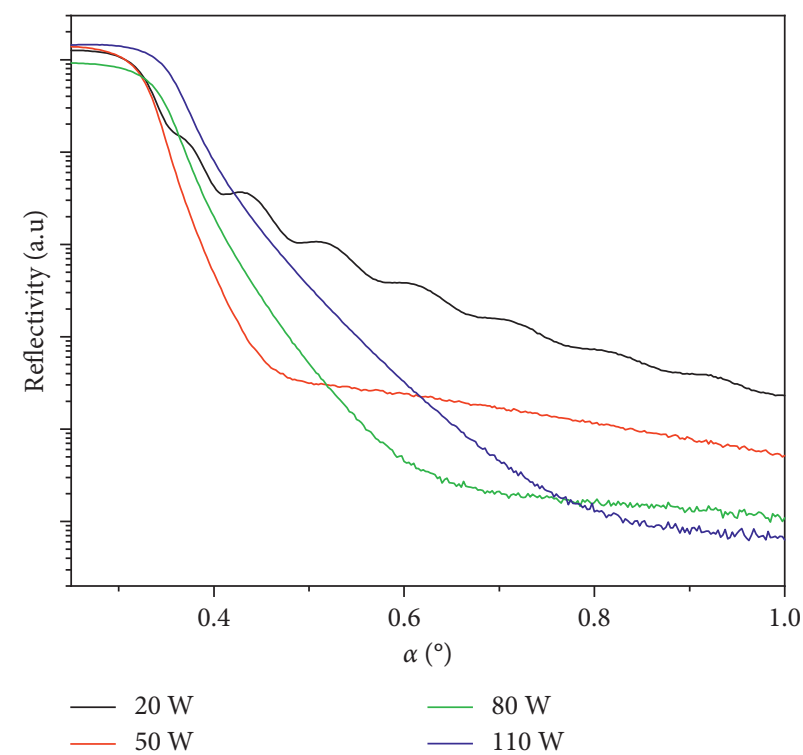

(b)

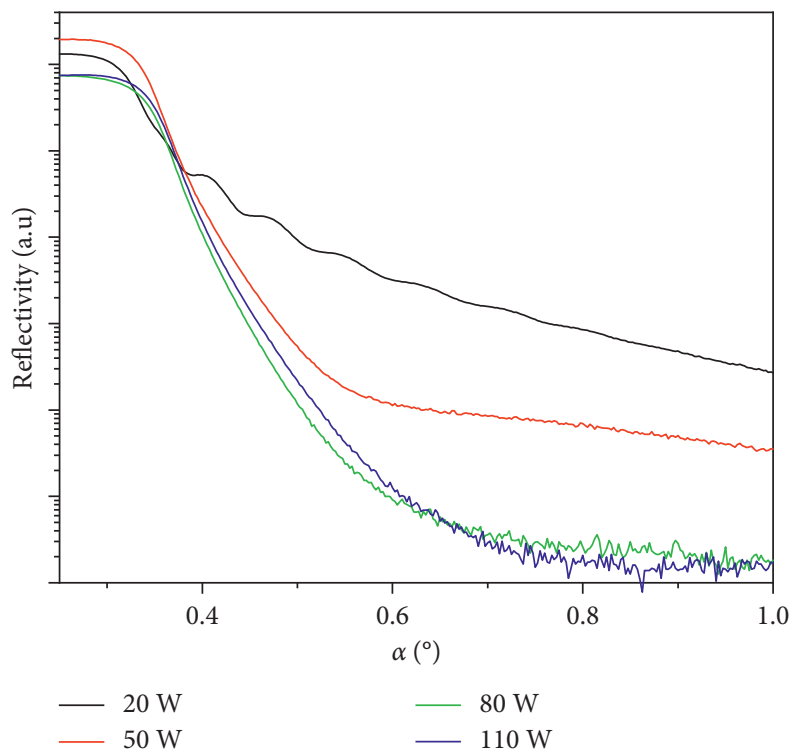

(c)

FIGURE 5: XRR spectra for the ITO films deposited with various powers and different deposition times: (a) 20 min; (b) 40 min; (c) 60 min.

$$
\begin{aligned}
& n=1-\delta+i \beta, \\
& \theta_{c}=\sqrt{2 \delta}, \\
& \theta_{c}=\sqrt{\frac{r_{e} \lambda^{2}}{\pi} \cdot N(Z+\Delta f),} \\
& \theta_{c}=\sqrt{\frac{r_{e} \lambda^{2}}{\pi} \cdot \frac{N_{A}}{M}(Z+\Delta f) \rho,}
\end{aligned}
$$

$$
\begin{aligned}
\frac{(Z+\Delta f)}{M} & =\frac{\sum_{i} c_{i}\left(Z_{i}+\Delta f_{i}\right)}{\sum_{i} c_{i} M_{i}}, \\
\rho & =\frac{\theta_{c}^{2} \pi}{r_{e} \lambda^{2} N_{A}} \cdot \frac{M}{(Z+\Delta f)} .
\end{aligned}
$$

In equation (6), $r_{\mathrm{e}}$ is the Bohr radius $\left(2.29 \times 10^{-1} \AA\right)$, $N(Z+\Delta f)$ is the electron density, $\lambda$ is the wavelength $(\lambda=$ $1.5413 \AA$ ) of XRD, $Z i$ is the atomic number, $M i$ is the atomic weight, $C i$ is the atomic ratio, and $\Delta \mathrm{fi}$ is the correction factor of the abnormal dispersion of the refractive index. The variations of films density, for various RF powers and 


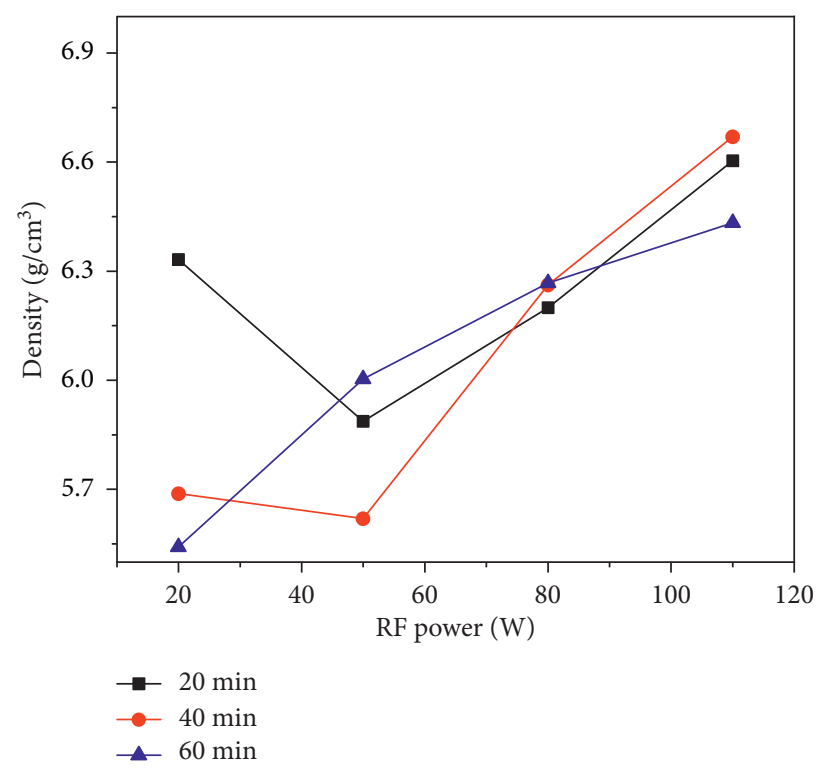

FIGURE 6: Density of the ITO films deposited with various powers and different deposition times.

different deposition times, are reported in Figure 6. We note that the density generally increases with increasing the $R F$ power. On the other hand, the minimum density of ITO films is $5.6 \mathrm{~g} \mathrm{~cm}^{-3}$ for $(20 \mathrm{~W}, 60 \mathrm{~min})$, and the maximum density reached $6.7 \mathrm{~g} \cdot \mathrm{cm}^{-3}$ for $(110 \mathrm{~W}, 40 \mathrm{~min})$.

Figure 7 shows the SEM images for the ITO films deposited with different powers and different deposition times. As can be seen, the images are different indicating that there is an influence of the thin film thickness and the RF power on the grain size and the crystallinity of the films. On the other hand, small circles at the nanoscale are seen. This result is in agreement with the XRD analysis.

The energy dispersion spectroscopy (EDX) technique was used to determine the chemical composition of our sample, which is shown in Figure 8. This confirms the presence of In, Sn, and O in the prepared ITO thin films. The peak of $\mathrm{Si}$ is due to the substrate elements. In addition, the percentage of elements (see Table 2) shows that the film corresponds to the ITO compound.

3.2. Optical Properties. The optical transmittance spectra of ITO films deposited with various powers and different deposition times in the 200-2000 $\mathrm{nm}$ wavelengths range are reported in Figure 9. Interference fringes are observed in the transmittance spectra for the powers greater than $20 \mathrm{~W}$. The transmittance spectra were used to determine the band gap and the Urbach energy [33]. In addition, the interference fringes were used to calculate the refractive index $n$, the absorption coefficient $k$, and the thickness $d$ of the thin films $[34,35]$. It is clear that the transmittance of ITO films decreases with increasing deposition power and the time. This is due to the increase in the film thickness with increasing RF power and/or deposition time as shown in Figure 10(a). Furthermore, it should also be noted that the average transmittance decreases with increasing RF power and/or deposition time and varies between $70 \%$ and $95 \%$ as shown in Figure 10(b). Moreover, ITO thin films have an allowed direct transition wide band gap. Consequently, ITO thin films have a good optical quality in the visible region [36].

The optical absorption coefficient and band gap are determined using the Lambert-Beer equation and the Tauc equation:

$$
\begin{gathered}
\alpha=\frac{\ln (1 / T)}{d}, \\
(\alpha h v)^{n}=A(h v-\mathrm{Eg}) .
\end{gathered}
$$

In the above equations, $T$ is the transmittance, $A$ is the constant, $h v$ the photon energy, and $n$ takes one of the values $2,2 / 3,1 / 2$, and $1 / 3$, for direct or for allowed direct, forbidden direct, allowed indirect, and forbidden indirect electronic transitions, respectively [37]. ITO is an $n$-type semiconductor with a direct band gap material for which $n=2$. Band gap can be determined by extrapolating the linear part of the curve $(\alpha h v)^{2}$ vs $h v$ to the energy axis.

The evolution of the band gap as a function of the RF power for different deposition times is shown in Figure 11(a). It is observed that the band gap is in the range $3.5-3.6 \mathrm{eV}$, which is in good agreement with the experimental values reported by other researchers [38-40]. In order to obtain further information about structural properties, the relationship between the absorption coefficient and photon energy is known as the Urbach empirical rule which is given by the following equation [41-43]:

$$
\begin{array}{r}
\alpha=\alpha_{0} \exp \left(\frac{h v}{E_{u}}\right), \\
\ln (\alpha)=\frac{h v}{E_{u}}+\ln \left(\alpha_{0}\right) .
\end{array}
$$



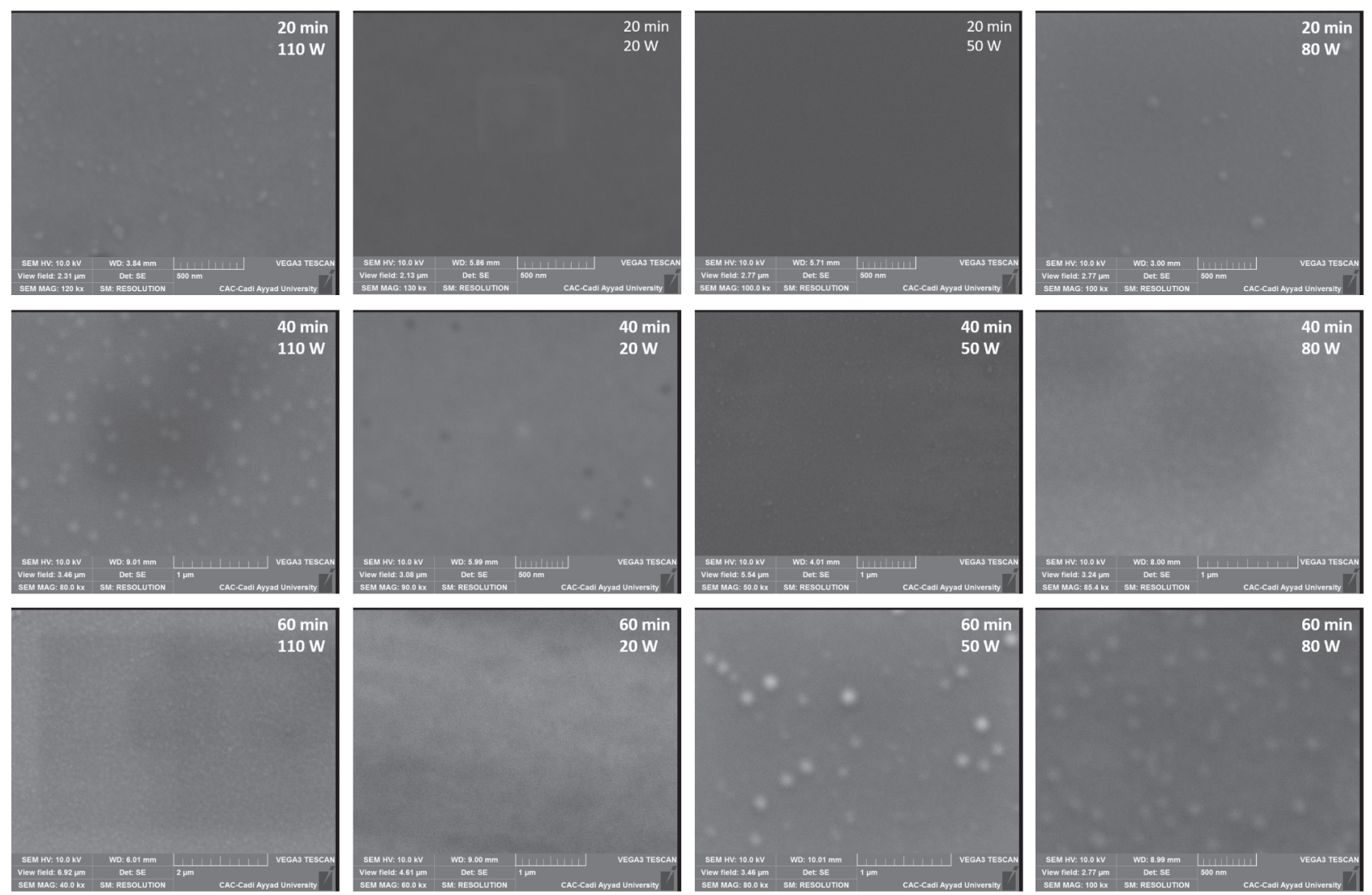

FIGURE 7: SEM images for ITO films deposited with various powers and different deposition times.

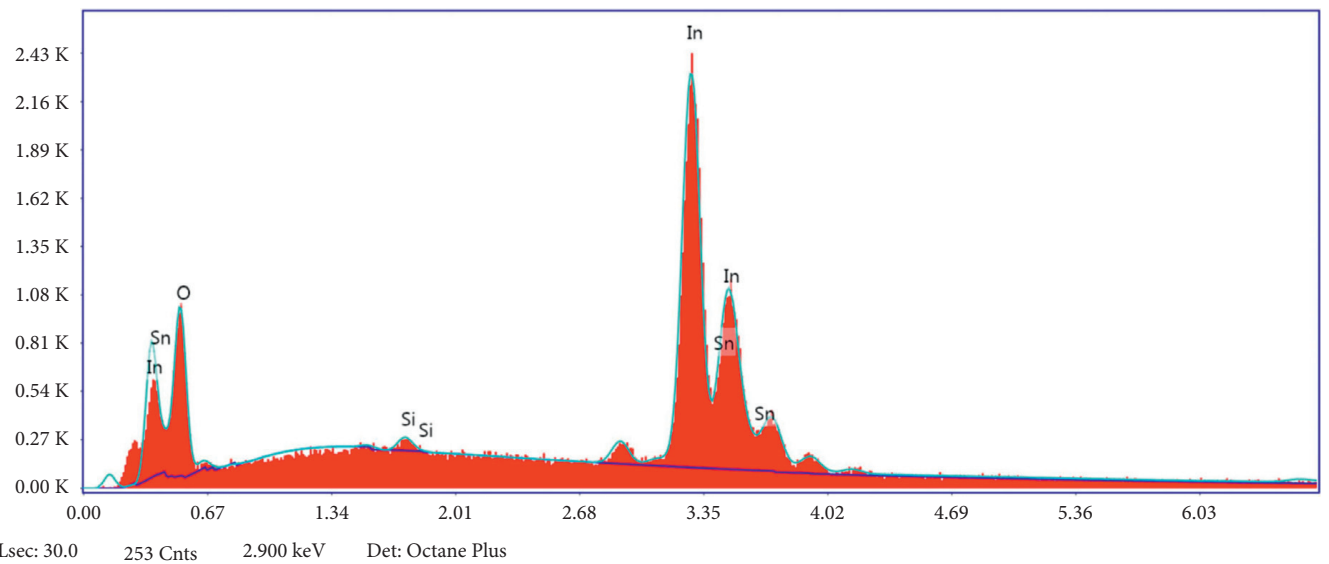

FIgURE 8: Energy dispersive X-ray (EDX) spectra of ITO films deposited with 60 min and $110 \mathrm{~W}$.

TABle 2: Composition of ITO films deposited with $60 \mathrm{~min}$ and $110 \mathrm{~W}$.

\begin{tabular}{lcc}
\hline Element & Weight (\%) & Atomic (\%) \\
\hline O K & 16.59 & 58.36 \\
SiK & 0.55 & 1.10 \\
InL & 77.85 & 38.17 \\
SnL & 5.01 & 2.38 \\
\hline
\end{tabular}

In equation (10), $h v$ is the photon energy, $\alpha_{0}$ is the constant, and $E_{u}$ is the band tail (Urbach energy). The band tail depends on temperature, induced disorder, strong ionic bonds, static disorder, and average photon energies as shown in Figure 11(b). The $E_{u}$ value is calculated from the slope of the straight line by plotting $\ln \alpha$ 


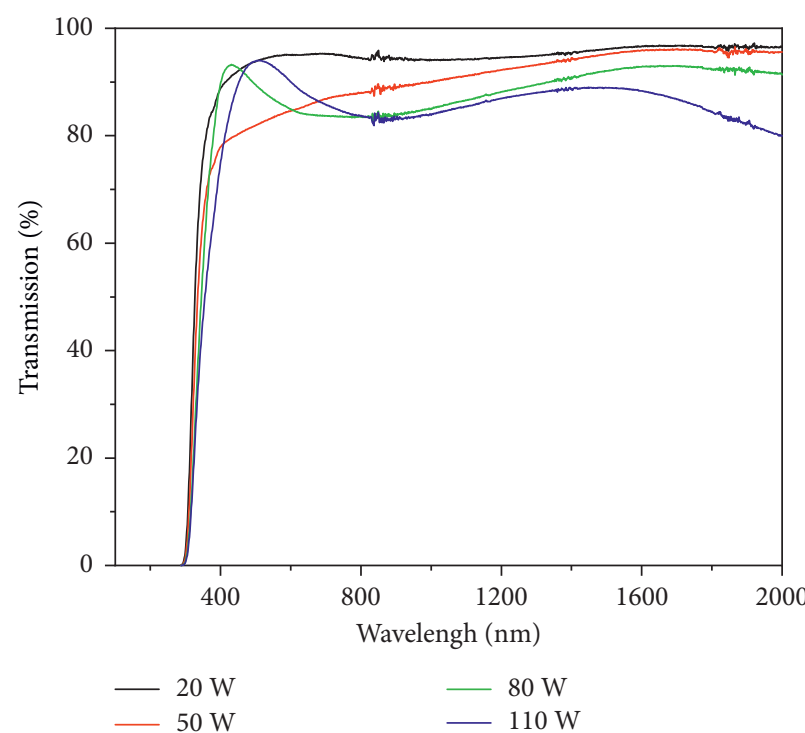

(a)

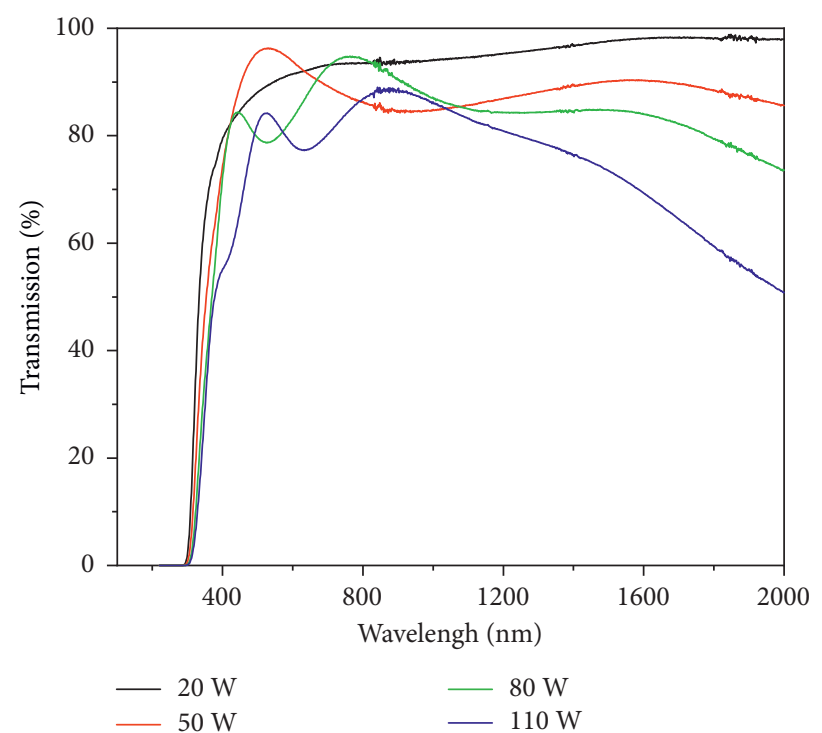

(b)

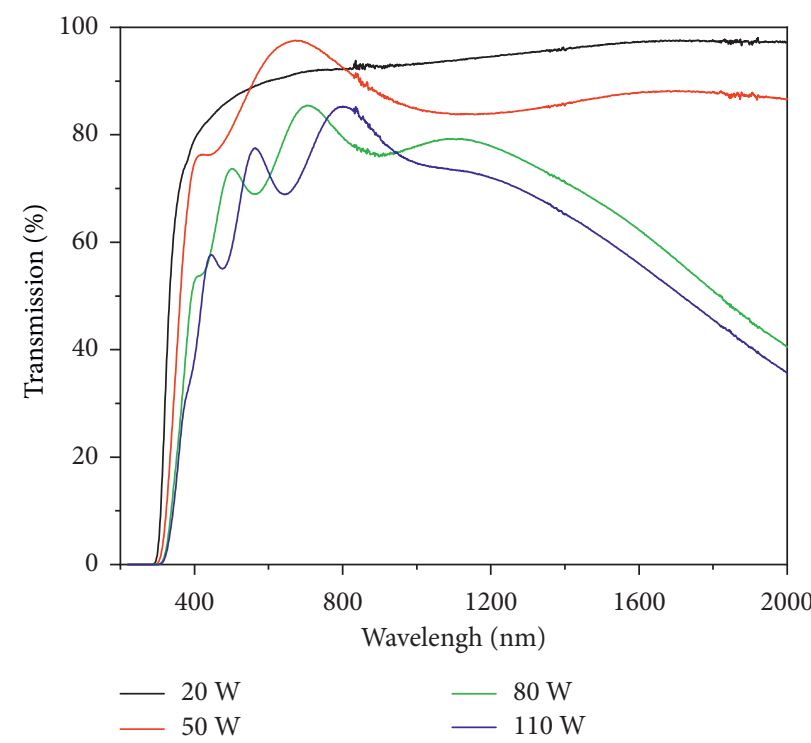

(c)

Figure 9: Transmittance of the ITO films deposited with various powers and different deposition times: (a) $20 \mathrm{~min}$; (b) $40 \mathrm{~min}$; (c) $60 \mathrm{~min}$.

versus $h v$. It should be noted that using the power of $50 \mathrm{~W}$ and $20 \mathrm{~min}$ results in a high band tail. This result is consistent with the results of XRD.

One of the parameters most influencing the efficiency of the solar cell and which allows to reduce the optical losses in the solar cell is the refractive index $n$. The expression of the latter is given by the following relations $[44,45]$ :

$$
\begin{aligned}
& n=\frac{2-T}{T}+\sqrt{\frac{4(1-T)}{T^{2}}-k^{2},} \\
& n=n(\infty)+\frac{b}{\lambda^{2}} .
\end{aligned}
$$

In equation (11), $b$ is the constant, $T$ is the transmittance, $k$ is extinction coefficient, and $n(\infty)$ is the value of the refractive index in the infrared region. Figure 12 shows the refractive index as a function of the wavelength. The refractive index increases as a function of the power. In addition, the refractive index increases by increasing the deposition time in the visible and infrared regions because of the effect of thickness and density. The refractive index in the infrared range has a value, which varies between 1.75 and 3 . This result is consistent with that reported by other researchers $[17,46]$.

In order to attain the detailed optical information, the extinction coefficient $k$ of the ITO films can be obtained from the following relationship: 


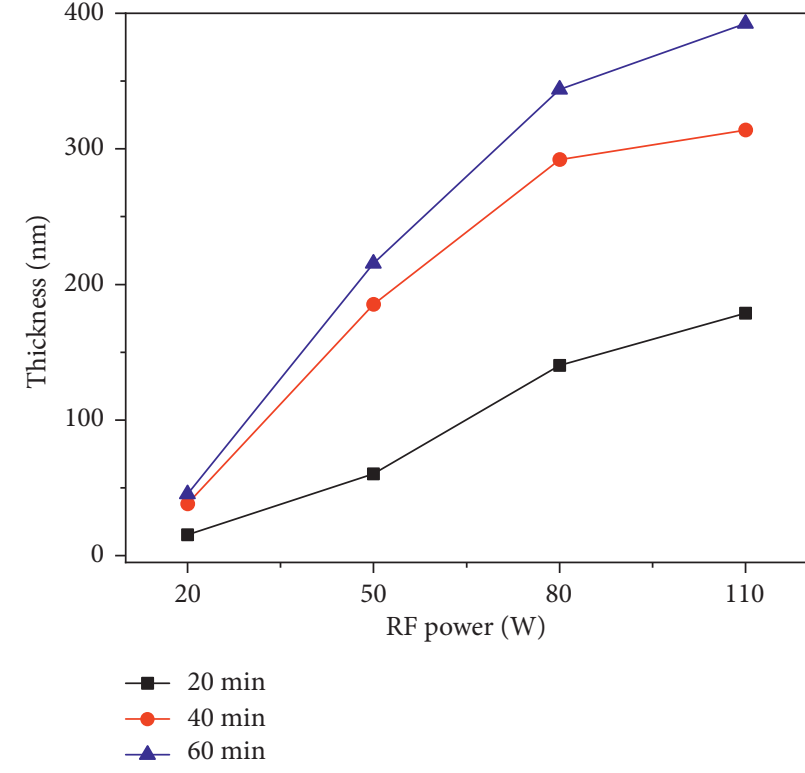

(a)

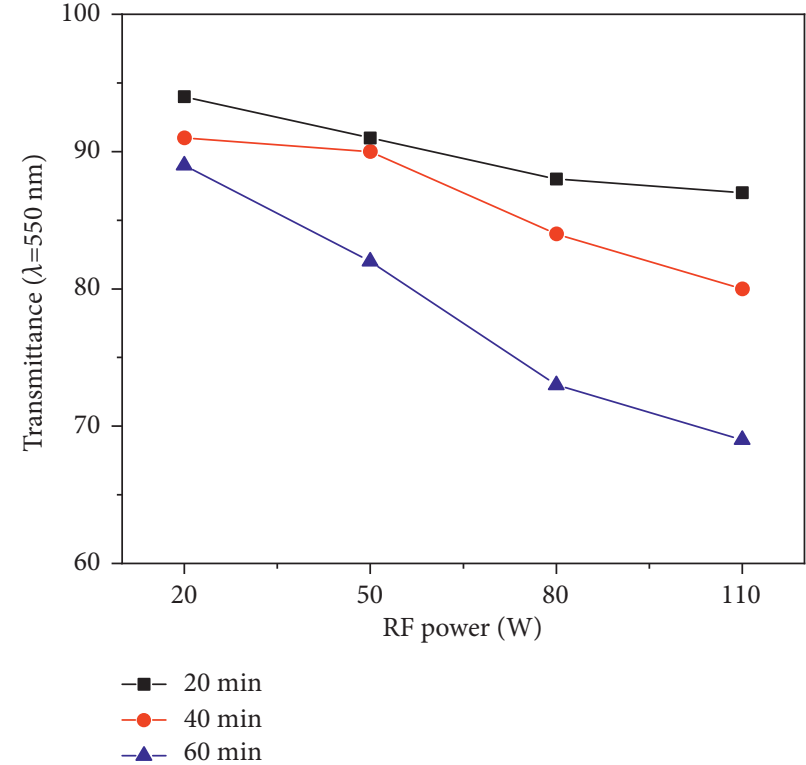

(b)

FIgURe 10: (a) Evolution of thickness and (b) transmittance of the ITO films with various powers and different deposition times.

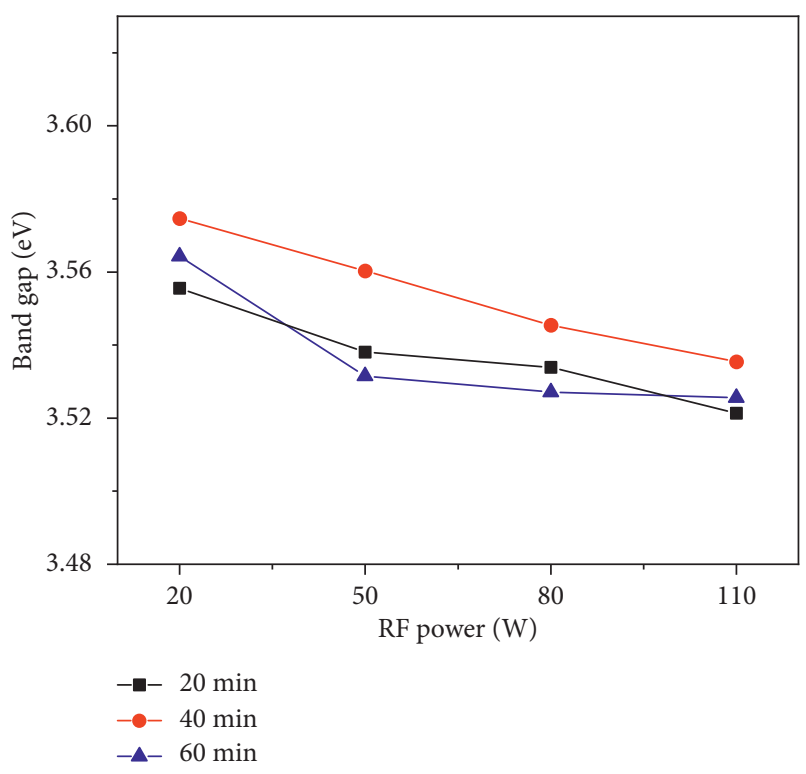

(a)

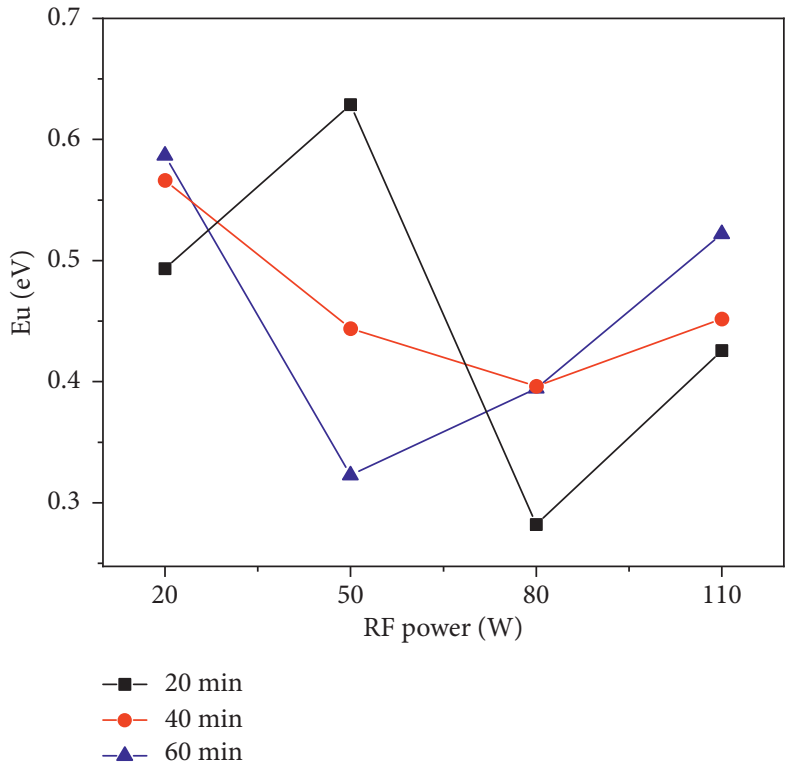

(b)

FIgURE 11: (a) Band gap and (b) Energy Urbach of the films deposited with various RF powers and different deposition times.

$$
k=\frac{\alpha \lambda}{4 \pi}
$$

where $\alpha$ is the absorption coefficient, and the variation of the extinction coefficient $k$ of the ITO films deposited with various powers and different deposition times is reported in Figure 13. We notice the thin film of ITO is not absorbent in the visible range and the extinction coefficient is in the order of $10^{-1}$. In the infrared range, the extinction coefficient increases with increasing the RF power and/or the deposition time because of the variation in thickness. This result is consistent with previous studies $[47,48]$.

3.3. Electrical Resistivity. The electrical resistivity of the films deposited with various RF powers and different deposition 


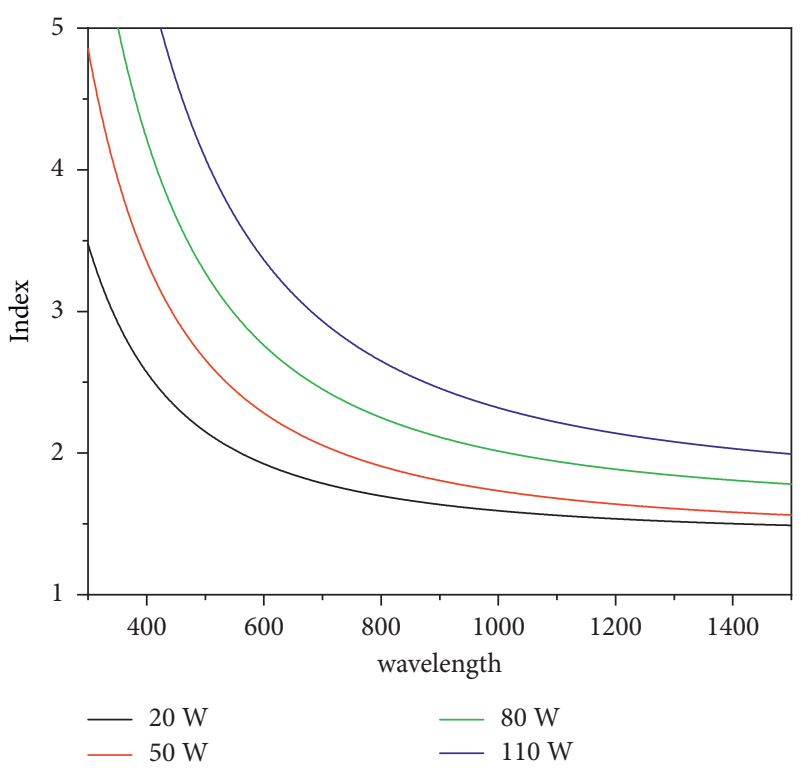

(a)

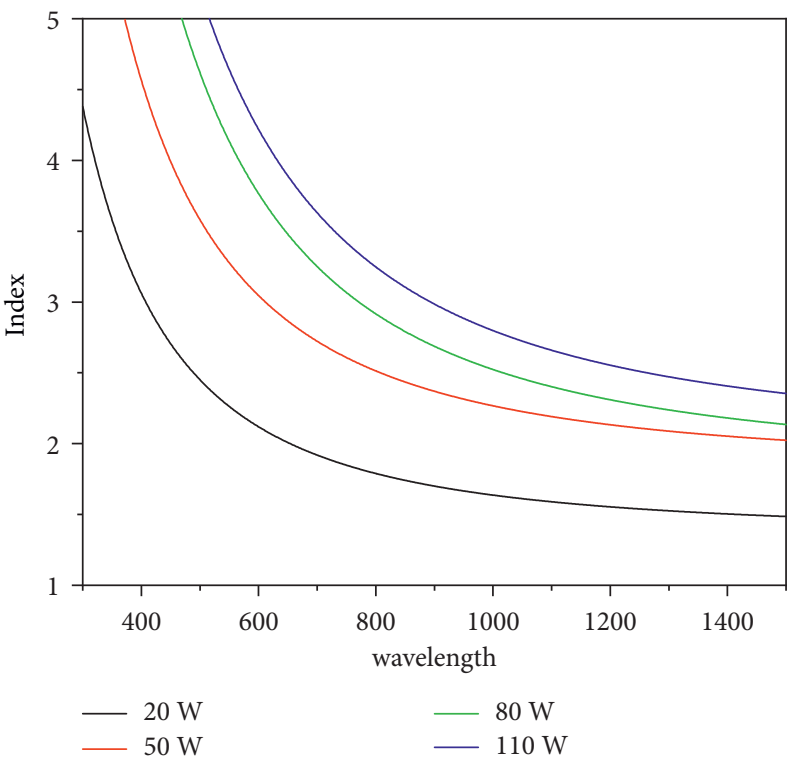

(b)

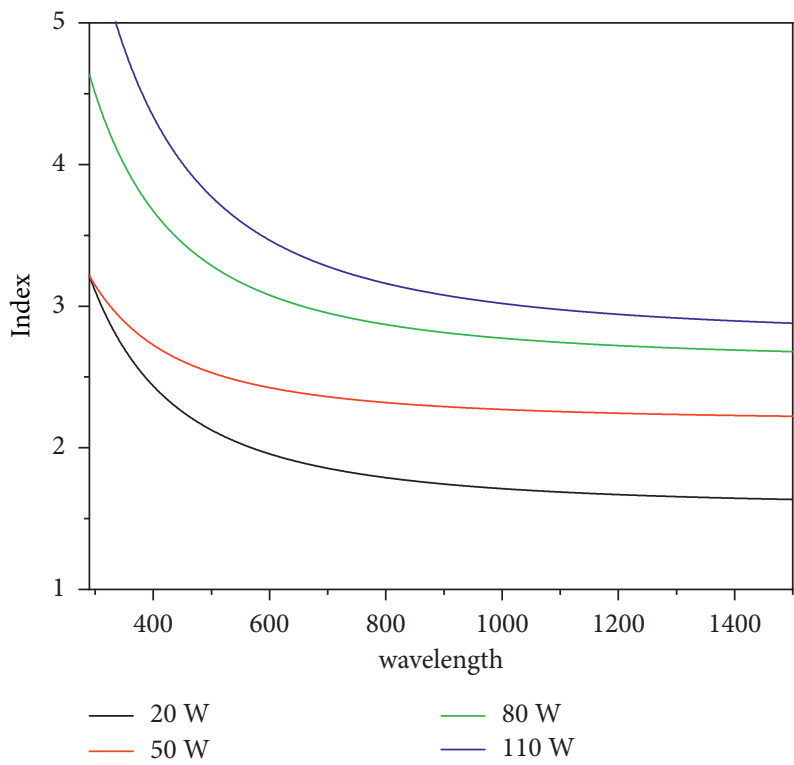

(c)

FIGURE 12: Refractive index of the ITO films deposited with various powers and different deposition times: (a) 20 min; (b) 40 min; (c) 60 min.

times is measured using the four-point probe, and the expression used is as follows:

$$
\rho=\frac{2 \pi \mathrm{d}}{\ln \left[\left(S_{1}+S_{2}\right)\left(S_{2}+S_{3}\right) / S_{1} S_{3}\right]} \frac{V}{I}
$$

where $\rho$ is the resistivity, $V$ is the voltage measured by the voltmeter, $I$ is the current intensity measured by the ammeter, and $S_{1}, S_{2}$, and $S_{3}$ are the distances between the probes.

The evolution of the sheet resistance and the electrical resistivity as a function of powers and different deposition times is shown in Figure 14. It can be clearly seen that the sheet resistance decreases with increase in the RF power and/ or the deposition time. The minimal resistivity is of $\approx 10^{-4} \Omega . \mathrm{cm}$, and it corresponds to the sample prepared without annealing. In addition, the resistivity rapidly decreases to the value $10^{-3} \Omega$.cm corresponding to the power of $50 \mathrm{~W}$; the power after it has a slight decrease. Moreover, the increase in resistivity is due to the increase in carrier concentration as a function of power [49]. On the other hand, the decrease in the resistivity is because of the decrease in the band gap (the obvious red shift). In addition, this result is consistent with the results of the optical properties. In fact, a large crystallite contains numerous atoms, with numerous overlaps between orbits, which results in the decrease in the optical band gap and hereby a low resistivity. It is obvious that the energy gap decreases when electron density increases. 


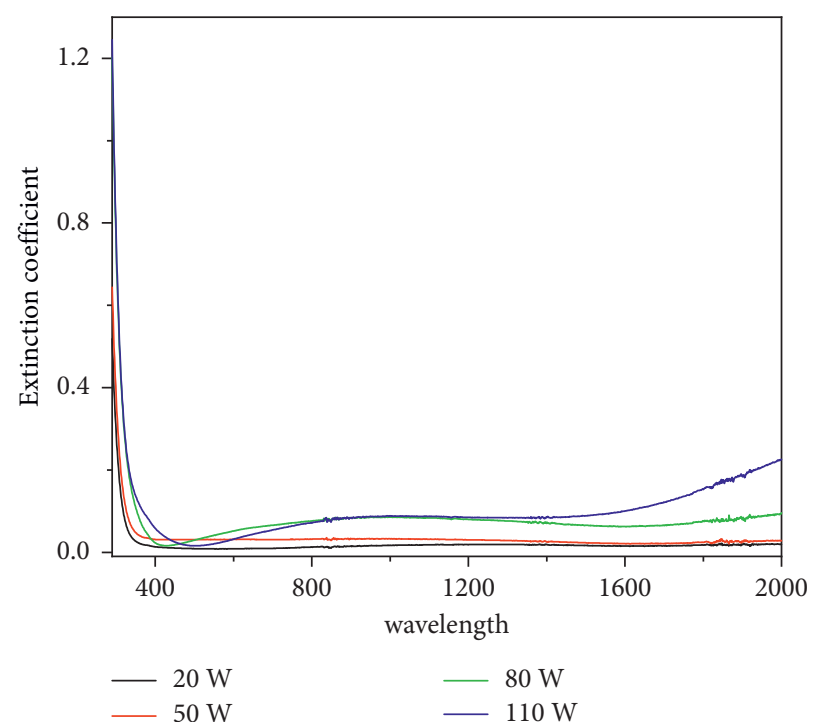

(a)

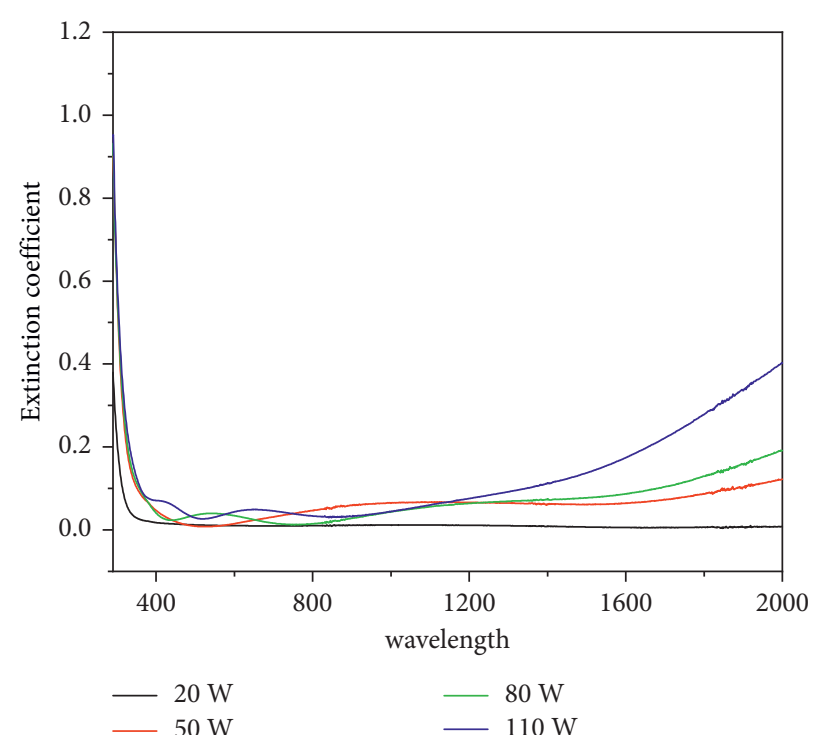

(b)

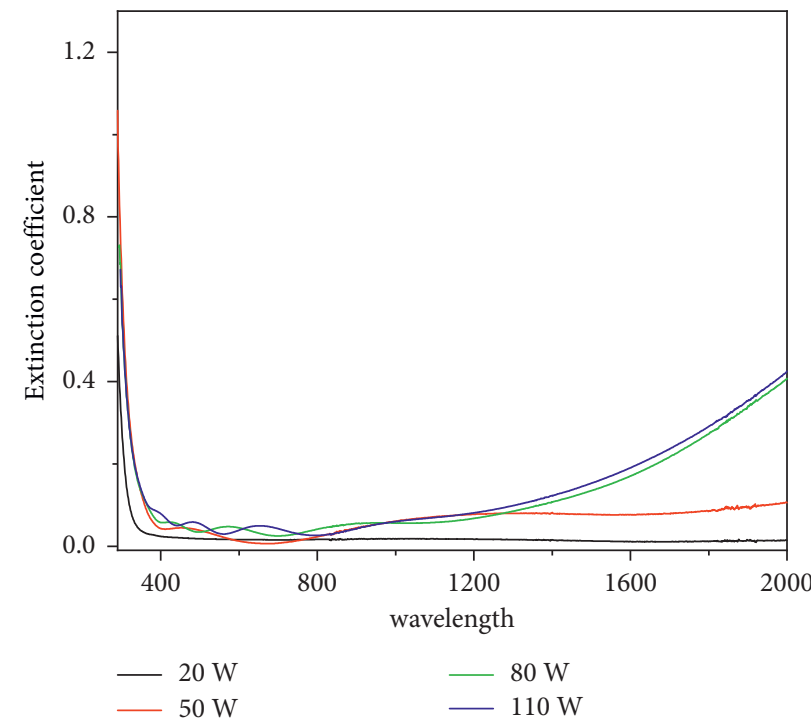

(c)

FIGURE 13: Extinction coefficient of the ITO films deposited with various powers and different deposition times: (a) 20 min; (b) 40 min; (c) $60 \mathrm{~min}$.

The ITO is widely used in solar cells. To determine the efficiency of ITO in usage as a front contact, the figure_of_merit (FOM) parameter was determined by the Haacke as follows [50]:

$$
\phi=\frac{T_{a}}{R_{\mathrm{sh}}}
$$

where $R_{\mathrm{sh}}$ the sheet resistance of the films ITO and $T_{a}$ is the average transmittance in the visible range (we take the average transmittance for thin film applications in solar cells). FOM is an important value for estimating the quality of transparent conducting oxide (TCO) films. Table 2 illustrates the figure_of_merit of the ITO as a function of the various $R F$ powers and different deposition times [16]. In this work, we obtain that FOM increases as a function of the various $R F$ powers and different deposition times. The best values of FOM are obtained when the power is $110 \mathrm{~W}$.

Table 3 illustrates the carrier concentration and Hall mobility of the ITO as a function of the various $R F$ powers and different deposition times. It is clear that the carrier concentration increases with increasing the RF power and/ or deposition time. The increase in carrier concentration can be explained by increasing of oxygen vacancies as donors and the decreasing of In or Sn bivalents as acceptors [39]. On the other hand, in $20 \mathrm{~W}$ films, the low crystallinity of ITO thin films is also the reason for the decrease in Hall mobility. This result is consistent with the results of XRD. In addition, there are a large number of defects in thin films, which is 


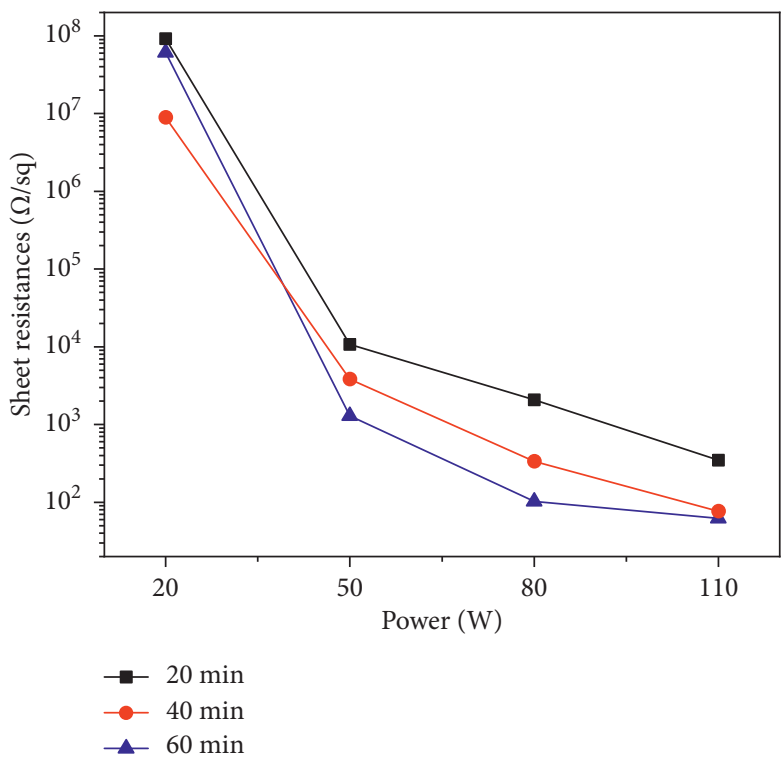

(a)

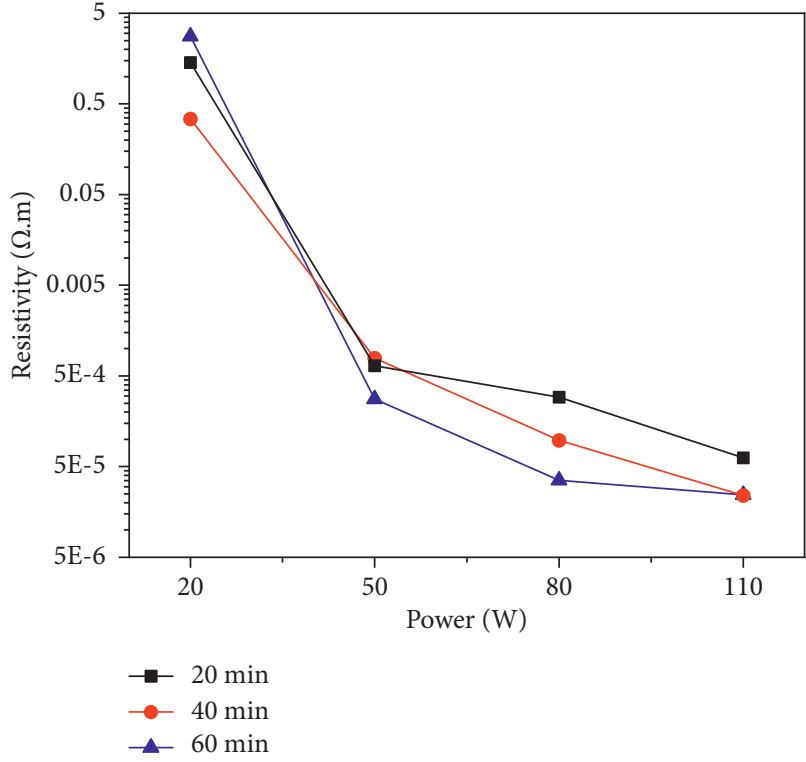

(b)

FIGURE 14: (a) Sheet resistance and (b) resistivity of the films deposited with various $R F$ powers and different deposition times.

TABLE 3: Carrier concentration, Hall mobility, and figure_of_merit for the ITO films deposited with various RF powers and different deposition times.

\begin{tabular}{|c|c|c|c|c|}
\hline Deposition times & RF power $(\mathrm{W})$ & $\begin{array}{c}\text { Carrier concentration } \\
\left(\times 10^{19} \mathrm{~cm}^{-3}\right)\end{array}$ & $\begin{array}{c}\text { Hall mobility }\left(\mathrm{cm}^{2} /\right. \\
\text { V.s })\end{array}$ & Figure_of_merit $(\mathrm{FOM}) \varphi\left(\times 10^{-4}\right.$ sq. $\left.\Omega^{-1}\right)$ \\
\hline \multirow{4}{*}{$20 \mathrm{~min}$} & 20 & - & - & 0.0001 \\
\hline & 50 & 0.03 & 7.8 & 0.8 \\
\hline & 80 & 0.10 & 1.77 & 4.2 \\
\hline & 110 & 0.97 & 9 & 24.9 \\
\hline \multirow{4}{*}{$40 \mathrm{~min}$} & 20 & - & - & 0.001 \\
\hline & 50 & 0.05 & 6.1 & 2.363 \\
\hline & 80 & 0.56 & 14.8 & 25.792 \\
\hline & 110 & 13.58 & 13.7 & 101.463 \\
\hline \multirow{4}{*}{$60 \mathrm{~min}$} & 20 & - & - & 0.0001 \\
\hline & 50 & 0.18 & 3.4 & 6.4 \\
\hline & 80 & 9.36 & 8.83 & 71.1 \\
\hline & 110 & 19.41 & 8.4 & 111.0 \\
\hline
\end{tabular}

agreed by the $E_{u}$ values. The greatest Hall mobility and concentration of charge carriers were obtained when the power is $110 \mathrm{~W}$. We conclude that the optimal parameters for good optical and high electrical properties are $110 \mathrm{~W}$ and $60 \mathrm{~min}$.

\section{Conclusion}

Structural, morphological, optical, and electrical properties of ITO thin film are investigated, as a function of the RF power and deposition time. It is shown that the RF power must exceed $20 \mathrm{~W}$ to have crystalline samples with orientation (222). The crystallite size increases with increasing the deposition time. On the other hand, the average transmission and the sheet resistance are decreased by increasing the RF power and/or the deposition time. The best FOM of ITO films is obtained using a power of $110 \mathrm{~W}$. ITO is not absorbent in the visible range, and the extinction coefficient is of the order of $10^{-1}$. This study revealed that ITO films have excellent optical and electrical properties for photovoltaic cells and optoelectronic applications.

\section{Data Availability}

The data used to support the findings of this study are available from the corresponding author upon request.

\section{Conflicts of Interest}

The authors declare that they have no conflicts of interest regarding the publication of this paper.

\section{Acknowledgments}

The authors are grateful to the Center of Analyses and Characterization (CAC) of University Cadi Ayyad, Marrakech, Morocco. 


\section{References}

[1] S. Li, X. Qiao, and J. Chen, "Effects of oxygen flow on the properties of indium tin oxide films," Materials Chemistry and Physics, vol. 98, no. 1, pp. 144-147, 2005.

[2] F. E. Akkad, A. Punnoose, and G. Prabu, "Properties of ITO films prepared by $\mathrm{rf}$ magnetron sputtering," Applied Physics A, vol. 160, no. 71, pp. 157-160, 2000.

[3] D. L. Xiao and Z. Dacheng, "Properties of nanosized tin oxide thin film prepared by reactive magnetron sputtering," in Proceedings of the International Conference on Integration and Commercialization of Micro and Nanosystems, pp. 1395-1400, Sanya, Hainan, China, January 2007.

[4] G. D. Gizem and Ö. D. Coskun, "The effect of annealing on the structural, electrical, optical and electrochromic properties of indium-tin-oxide films deposited by RF magnetron sputtering technique," Optik, vol. 142, pp. 320-326, 2017.

[5] J. Li, C. Mu, and X. Li, "Structure and physical properties evolution of ITO film during amorphous- crystalline transition using a highly effective annealing technique," Ceramics International, vol. 45, no. 13, Article ID 16214, 2019.

[6] Y. Park, Y. Kim, H. Seo, S. G. Ansari, and H. Shin, "ITO thin films deposited at different oxygen flow rates on $\mathrm{Si}$ (100) using the PEMOCVD method," Surface and Coatings Technology, vol. 161, no. 1, pp. 62-69, 2002.

[7] D. H. Kim, M. R. Park, H. J. Lee, and G. H. Lee, “Thickness dependence of electrical properties of ITO film deposited on a plastic substrate by RF magnetron sputtering," Applied Surface Science, vol. 253, no. 2, pp. 409-411, 2006.

[8] S. Il, S. Hyun, S. Ryong, H. Ho, and P. Keun, "Properties of ITO films deposited by RF superimposed DC magnetron sputtering," Current Applied Physics, vol. 9, no. 3, pp. S262-S265, 2009.

[9] D. Kim, M. Park, and G. Lee, "Preparation of high quality ITO films on a plastic substrate using RF magnetron sputtering," Surface and Coatings Technology, vol. 201, no. 3-4, pp. 927931, 2006.

[10] O. Tuna, Y. Selamet, G. Aygun, and L. Ozyuzer, "High quality ITO thin films grown by dc and RF sputtering without oxygen," Journal of Physics D Applied Physics, vol. 43, no. 5, 2010.

[11] H. Koseoglu, M. Kurt, M. D. Yaman, F. Turkoglu, F. G. Akca, and L. Ozyuzer, "Improvement of optical and electrical properties of ITO thin films by electro-annealing," Vacuum, vol. 120, pp. 8-13, 2015.

[12] A. K. John, V. V. Kumar, M. Deepak, and T. Manju, "Influence of sputtering power on the optical properties of ITO thin films preparation of ITO thin films," AIP Conference Proceedings, vol. 1620, no. 22, pp. 22-27, 2014.

[13] A. Chaoumead, Y. Sung, and D. Kwak, "The effects of RF sputtering power and gas pressure on structural and electrical properties of ITiO thin film," Advances in Condensed Matter Physics, vol. 2012, Article ID 651587, 7 pages, 2012.

[14] M. Ahmadipour, M. F. Ain, S. Goutham, and Z. A. Ahmad, "Effects of deposition time on properties of CaCu3Ti4O12 thin film deposited on ITO substrate by RF magnetron sputtering at ambient temperature," Ceramics International, vol. 44, no. 15, pp. 18817-18820, 2018.

[15] T. Chaikeeree, P. Nachuay, and M. Narong, "Enhanced transmission based on vertically aligned ITO NRs deposited by Ion assisted electron beam evaporation with glancing angle deposition technique," Mater Today Proceedings, vol. 4, no. 5, pp. 6060-6064, 2017.

[16] L. A. Fraga, F. J. Villacorta, and J. S. Macrcos, "Indium-tin oxide thin films deposited at room temperature on glass and
PET substrates : optical and electrical properties variation with the H 2 - Ar sputtering gas mixture," Applied Surface Science, vol. 344, pp. 217-222, 2015.

[17] J. Kim, H. J. Seo, H. K. Kim et al., "The effects of film thickness on the electrical, optical, and structural properties of cylindrical, rotating, magnetron-sputtered ITO films," Applied Surface Science, vol. 440, pp. 1211-1218, 2018.

[18] M. Nisha, S. Anusha, A. Antony, R. Manoj, and M. K. Jayaraj, "Effect of substrate temperature on the growth of ITO thin films," Applied Surface Science, vol. 252, no. 5, pp. 1430-1435, 2005.

[19] C. N. D. Carvalho, A. Luis, G. Lavareda, E. Fortunato, and A. Amaral, "Effect of thickness on the properties of ITO thin films deposited by RF- PERTE on unheated, flexible, transparent substrates," Surface and Coatings Technology, vol. 152, pp. 252-256, 2002.

[20] J. C. Manifacier, L. Szepessy, L. F. Bresse, and M. Perotin, "In203: (Sn) and SnO2: (F) films - application to solar energy conversion part II - electrical and optical properties," Materials Research Bulletin, vol. 14, no. 2, pp. 163-175, 1979.

[21] M. Sobri, V. Ganesh, and K. M. Hakim, "Effect of annealing on structural, optical, and electrical properties of nickel (Ni)/ indium tin oxide (ITO) nanostructures prepared by RF magnetron sputtering," Superlattices and Microstructures, vol. 70, pp. 82-90, 2014.

[22] A. A. Hadi, H. Zainuriah, and A. Shuhaimi, "Enhancement of optical transmittance and electrical resistivity of postannealed ITO thin films RF sputtered on Si," Applied Surface Science, vol. 443, pp. 544-547, 2018.

[23] B. Mayer, "Highly conductive and transparent films of tin and fluorine doped indium oxide produced by APCVD," Thin Solid Films, vol. 221, no. 1-2, pp. 166-182, 1992.

[24] P. Nath and R. F. Bunshah, "Preparation of In203 and tindoped In 203 films by a novel activated reactive evaporation technique," Thin Solid Films, vol. 69, no. 1, pp. 63-68, 1980.

[25] A. Suzuki, T. Matsushita, T. Aoki, A. Mori, and M. Okuda, "Highly conducting transparent indium tin oxide films prepared by pulsed laser deposition," Thin Solid Films, vol. 411, no. 1, pp. 23-27, 2002.

[26] L. Voisin, M. Ohtsuka, S. Petrovska, and R. Sergiienko, "Structural, optical and electrical properties of DC sputtered indium saving indium-tin oxide (ITO) thin films," Optik, vol. 156, pp. 728-737, 2018.

[27] L. Kerkache, A. Layadi, and A. Mosser, "Effect of oxygen partial pressure on the structural and optical properties of $\mathrm{dc}$ sputtered ITO thin films," Journal of Alloys and Compounds, vol. 485, no. 1, pp. 46-50, 2009.

[28] F. Kurdesau, G. Khripunov, A. F. D. Cunha, M. Kaelin, and A. N. Tiwari, "Comparative study of ITO layers deposited by DC and RF magnetron sputtering at room temperature," Journal of Non-Crystalline Solids, vol. 352, pp. 1466-1470, 2006.

[29] T. Arockiadoss, M. Kovendhan, D. P. Joseph, A. S. Kumar, B. Chun, and K. S. Shim, "Applied Surface Science DC magnetron sputtered aligned ITO nano-rods with the influence of varying oxygen pressure," Applied Surface Science, vol. 449, pp. 39-47, 2018.

[30] Z. Ghorannevis, E. Akbarnejad, and M. Ghoranneviss, "Structural and morphological properties of ITO thin films grown by magnetron sputtering," Journal Theory of Applied Physics, vol. 9, no. 4, pp. 285-290, 2015.

[31] E. Ech-chamikh, A. Essafti, and I. Youssef, "Une méthode simple et précise pour la détermination de l'épaisseur de couches ultraminces à partir des mesures de réflectométrie des 
rayons X Résumé,” Afrique Science, vol. 2, no. 3, pp. 255-262, 2006.

[32] C. M. S. Vall, M. Chaik, and A. Tchenka, "Effect of chromium percentage doping on the optical, structural, morphological and electrical properties of ZnS: Cr thin films," Physica E: Low-dimensional Systems and Nanostructures, vol. 130, Article ID 114694, 2021.

[33] A. E. Kissani, F. Weletta, and A. Khalfi, "A facile route for synthesis of cadmium sulfide thin films," Thin Solid Films, vol. 664, pp. 66-69, 2018.

[34] C. M. S. Vall, M. Chaik, and H. A. Dads, "Effect of RF power on the structural and optical properties of $\mathrm{ZnS}$ thin films prepared by RF-sputtering," Journal of Semiconductors, vol. 39, no. 12, Article ID 123001, 2018.

[35] A. E. Khalfi, E. E. chamikh, Y. Ijdiyaou, M. Azizan, and A. Essafti, "Optical properties of amorphous silicon - carbon alloys (a-Si x C 1 - x) deposited by RF Co-sputtering," Arabian Journal for Science and Engineering, vol. 39, no. 7, pp. 5771-5776, 2014.

[36] C. Coutal, A. Azéma, and J. C. Roustan, "Fabrication and characterization of ITO thin films deposited by excimer laser evaporation," Thin Solid Films, vol. 288, no. 1-2, pp. 248-253, 1996.

[37] B. Xu, X. Ren, G. Gu, L. Lan, and B. Wu, "Structural and optical properties of $\mathrm{Zn}$-doped $\mathrm{SnO} 2 \mathrm{fi} \mathrm{lms}$ prepared by DC and RF magnetron co-sputtering," Superlattices and Microstructures, vol. 89, pp. 34-42, 2016.

[38] M. G. Sousa and A. F. D. Cunha, "Optimization of low temperature RF-magnetron sputtering of indium tin oxide films for solar cell applications," Applied Surface Science, vol. 484, pp. 257-264, 2019.

[39] A. P. Amalathas and M. M. Alkaisi, "Effects of film thickness and sputtering power on properties of ITO thin films deposited by RF magnetron sputtering without oxygen," Journal of Materials Science: Materials in Electronics, vol. 27, no. 10, pp. 11064-11071, 2016.

[40] T. Arockiadoss, M. Kovendhan, D. P Joseph, and A. S. Kumar, "DC magnetron sputtered aligned ITO nano-rods with the influence of varying oxygen pressure," Applied Surface Science, vol. 449, pp. 39-47, 2017.

[41] E. Ech-chamikh, E. L. Amezianea, A. Bennounaa, M. Azizan, and T. A. N. Tanb, "Structural and optical properties of r.f.sputtered Si, C, _ x:0 films," Thin Solid Films, vol. 259, no. 1, pp. 18-24, 1995.

[42] B. Choudhury, M. Dey, and A. Choudhury, "Defect generation, $\mathrm{d}-\mathrm{d}$ transition, and band gap reduction in $\mathrm{Cu}$-doped TiO2 nanoparticles," International Nano Letters, vol. 3, no. 1, pp. 2-9, 2013.

[43] A. S. Hassanien and A. A. Akl, "Effect of Se addition on optical and electrical properties of chalcogenide CdSSe thin films," Superlattices and Microstructures, vol. 89, pp. 153169, 2016.

[44] A. Dahshan, H. H. Amer, and K. A. Aly, "Compositional dependence of the optical constants of amorphous Ge xAs20Se80-x thin films," Journal of Physics D Applied Physics, vol. 41 , no. $21,2008$.

[45] A. E. Hamidi, A. Liba, T. Jannane, E. Hichoua, and A. Mezianea, "Refractive index controlled by film morphology and free carrier density in undoped $\mathrm{ZnO}$ through sol-pH variation," Optik, vol. 158, pp. 1139-1146, 2018.

[46] K. J. Kumar, N. R. C. Raju, and A. Subrahmanyam, "Thickness dependent physical and photocatalytic properties of ITO thin films prepared by reactive DC magnetron sputtering," Applied Surface Science, vol. 257, no. 7, pp. 3075-3080, 2011.
[47] K. Deepa, K. C. Preetha, and K. V. Murali, "The effect of various complexing agents on the morphology and optoelectronic properties of chemically deposited ZnS Thin films," Optik, vol. 125, no. 19, pp. 5727-5732, 2014.

[48] D. Kudryashov, A. Gudovskih, and K. Zelentsov, "Low temperature growth of ITO transparent conductive oxide layers in oxygen-free environment by RF magnetron sputtering," Journal of Physics Conference Series, vol. 461, pp. 1-5, 2013.

[49] S. Yu, L. Li, X. Lyu, and W. Zhang, "Preparation and investigation of nano-thick $\mathrm{FTO} / \mathrm{Ag} / \mathrm{FTO}$ multilayer transparent electrodes with high figure of merit," Scientific Report, vol. 6 , no. 1 , pp. $1-8,2016$

[50] G. Haacke, "New figure of merit for transparent conductors," Journal of Applied Physics, vol. 47, no. 9, pp. 4086-4089, 1976. 